\title{
ANALISIS PRODUKTIVITAS DAN TEKNIS PENANGKAPAN RAWAI DASAR DI DESA KOTA BANI KECAMATAN PUTRI HIJAU KABUPATEN BENGKULU UTARA
}

\author{
Wisnu Linggo Franjaya, Zamdial, Ali Muqsit \\ Program Studi IImu Kelautan Universitas Bengkulu \\ E-mail: alimuqsit@gmail.com
}

Received August 2018, Accepted September 2018

\begin{abstract}
ABSTRAK
Pancing rawai dasar merupakan alat tangkap dominan yang digunakan oleh nelayan di Desa Kota Bani Kecamatan Putri Hijau Kabupaten Bengkulu Utara. Penelitian ini bertujuan untuk mendeskripsikan perikanan tangkap pancing rawai dasar di sentra perikanan Desa Kota Bani, Kecamatan Putri Hijau, Kabupaten Bengkulu Utara. Penelitian ini menggunakan metode Survei dengan teknik observasi dan wawacara. Analisis data dilakukan dengan metode statistik deskriptif. Hasil penelitian menunjukkan bahwa nilai produktivitas perikanan rawai dasar di Desa Kota Bani diperoleh nilai produktivitas per trip sebesar $3 \mathrm{~kg}$ dan produktivitas pertahun sebesar $6000 \mathrm{~kg}$. Ukuran alat tangkap pancing rawai di Desa Kota Bani Kecamatan Putri Hijau Kabupaten Bengkulu Utara dengan panjang tali utama rata-rata 1.000 meter, panjang tali cabang 1 depa atau 1,5 meter, mata pancing rata-rata 100 - 200 mata pancing, tanda atau bendera 2 buah, pelampung berjumlah rata-rata 5 buah, pemberat rata-rata berjumlah 5 . Ukuran kapal rata-rata panjang 10 meter, tinggi 1 meter, lebar 1,5 meter, dengan ukuran rata-rata adalah 3 GT. Mesin penggerak yang digunakan adalah mesin tempel $15 \mathrm{PK}$ dengan jenis BBM yang digunakan yaitu pertalite yang dicampurkan dengan oli merek Castrol 2T. Jumlah anak buah kapal (ABK) perahu/kapal nelayan penangkapan ikan berjumlah 2 orang dalam satu perahu/kapal. Metode pengoperasiaan Pancing Rawai Dasar dibagi menjadi 4 tahap, yaitu: Persiapan, Setting, Drafting dan Haulling. Kedalaman daerah penangkapan ikan nelayan berkisar antara 10 - 20 meter dengan ikan hasil tangkapan Pancing Rawai Dasar terdiri dari 5 jenis, yaitu ikan kakap merah (Lutjanus malabaricus), ikan manyung (Arius thalassinus), ikan kerapu (Epinephelus sp.), ikan hiu putih (Selachimorpha) dan ikan pari (Dasyatis sp.).
\end{abstract}

Kata Kunci : Drafting, Hauling, Pancing Rawai Dasar, Produktivitas, Setting 


\begin{abstract}
The bottom set longline is a fishing gear that used by fisherman in Kota Bani Village, Putri Hijau Subdistrict, North Bengkulu Regency. This study aims to describe capture fisheries of bottom set longline at fishery center of Kota Bani Village, Putri Hijau Subdistrict, North Bengkulu Regency. This research use Survey method with observation, interview and documentation technique. Data analysis using descriptive statistical methods. The results showed that the size of the bottom longine in Kota Bani Village, Putri Hijau Subdistrict, North Bengkulu Regency is the length of the main rope averaging 1,000 meters, the length of the branch line is 1 depa or 1.5 meters, average of 100 - 200 hooks, marks or flags of 2 pieces, floats averaged 5 pieces, average of 5 weights made of stone. The average size of the vessel is 10 meters long, 1 meter high, 1.5 meters wide, with the average size is 3 GT. The driving machine used is the outboard engine 15 PK with the type of fuel used is the Pertalite mixed with Castrol $2 T$ oil. The number of crew members on fishing boats/fishing vessels amounted to 2 persons in one boat/vessel. The operation method of the bottom set longline is divided into 4 stages, namely: Preparation, Setting, Drafting and Hauling. The depth of the fishing area ranges from 10 to 20 meters with the catch fish consists of 5 types, namely Red Snapper (Lutjanus malabaricus), Ariidae fish (Arius thalassinus), Grouper (Epinephelus sp.), White Shark (Selachimorpha) and Stingray (Dasyatis sp.). The marketing of the catches used by fishermen in Kota Bani Village, Putri Hijau Subdistrict, North Bengkulu Regency is conducted directly by the collecting traders and motorcycle baskets.
\end{abstract}

Keywords : Drafting, Hauling, Capture Fisheries, Productivity, Setting

\title{
PENDAHULUAN
}

Provinsi Bengkulu memiliki potensi yang cukup besar pada subsektor perikanan, terutama perikanan laut. Letak wilayah yang sebagian besar menghadap ke Samudera Hindia dengan panjang pantai mencapai $525 \mathrm{~km}$, sehingga Provinsi Bengkulu memiliki luas Laut Teritorial sebesar $53.000 \mathrm{~km}^{2}$ dan luas Zona Ekonomi Eksklusif (ZEE jarak 12-200 mil laut dari pantai) mencapai $685.000 \mathrm{~km}^{2}$ (Pemprov Bengkulu, 2018). Secara geografis Kecamatan Putri Hijau Kabupaten Bengkulu Utara terletak pada $101^{\circ} 33^{\prime} 14^{\prime \prime}-102^{0} 10^{\prime} 27^{\prime \prime}$ LS dan $20^{\circ} 44^{\prime} 29^{\prime \prime}-30^{\circ}$ 19' 10" BT dengan iklim 22-33 $\mathrm{C}$ dan curah hujantinggi (Bappeda Kabupaten Bengkulu Utara, 2016).

Kehidupan masyarakat di Kecamatan Putri Hijau yang mata pencahariaannya bervariasi mulai dari pedagang, petani, penambang dan nelayan. Terkhusus di Desa Kota Bani penduduknya adalah pedagang dan nelayan. Menurut Subri (2005) dalam Rosni (2017) Nelayan dibedakan menjadi tiga kelompok, yaitu nelayan buruh, nelayan juragan, 
dan nelayan perorangan. Nelayan di Desa Kota Bani menggunakan alat tangkap jaring insang (Gill net), pancing rawai (Long line) dasar dan alat tangkap lobster (bubu lobster).

Menurut Sadhori (1985), ada berbagai macam bentuk rawai yang secara keseluruhan dapat dikelompokkan dalam berbagai kelompok antara lain. Berdasarkan letak pemasangannya di perairan rawai dapat dibagi menjadi, rawai permukaan (Surface long line), rawai pertengahan (Midwater long line), rawai dasar (Bottom long line). Berdasarkan susunan mata pancing pada tali utama, rawai tegak (Vertikal long line), pancing ladung, rawai mendatar (Horizontal long line). Berdasarkan jenis-jenis ikan yang banyak tertangkap, rawai Tuna (Tuna long line), rawai Albacore (Albacore long line), rawai Cucut (Shark long line), dan sebagainya.

Setyorini dkk, (2009) menjelaskan Rawai Dasar (Bottom long line) merupakan alat tangkap yang cocok digunakan di perairan Indonesia, karena wilayah perairan yang luas dan kaya akan berbagai ikan dasar. Rawai (Long line) merupakan rangkaian dari unit-unit pancing yang sangat panjang (mencapai ribuan, bahkan puluhan ribu meter). Terdiri dari tali utama (main line), tali cabang (branch lines), dan mata pancing (hooks) dengan ukuran (nomor) tertentu yang diikatkan pada setiap ujung bawah tali-tali cabang (setiap cabang terdiri dari satu mata pancing). Ditinjau dari konstruksinya alat tangkap ini tidak terlalu rumit karena hanya terdiri dari 3 bagian, yaitu ; tali utama, tali cabang dan mata pancing. Sasaran penangkapan alat tangkap rawai pada umumnya ikan-ikan pemangsa dan memiliki pergerakan aktif (Syofyan $d k k$., 2015).

Tujuan penelitian ini adalah menganalisis produktivitas dan teknis penangkapan perikanan pancing rawai dasar di sentra perikanan Desa Kota Bani, Kecamatan Putri Hijau, Kabupaten Bengkulu Utara. Manfaat dari penelitian ini adalah : Memberikan informasi serta pengetahuan kepada nelayan pancing rawai dasar di Desa Kota Bani, Kecamatan Putri Hijau, Kabupaten Bengkulu Utara, dan memberikan gambaran serta penjelasan tentang perkembangan pancing rawai dasar kepada pemerintah dan stakeholder terkait. Sebagai dasar pengelolaan alat tangkap pancing rawai di Desa Kota Bani, Kecamatan Putri Hijau, Kabupaten Bengkulu Utara.

\section{MATERI DAN METODE}

\section{Waktu dan Tempat Penelitian}

Penelitian ini dilaksanakan pada bulan April sampai dengan Mei 2018, di Desa Kota Bani, Kecamatan Putri Hijau, Kabupaten Bengkulu Utara. Adapun lokasi pelaksanaan penelitian dapat di lihat pada Gambar 1. 


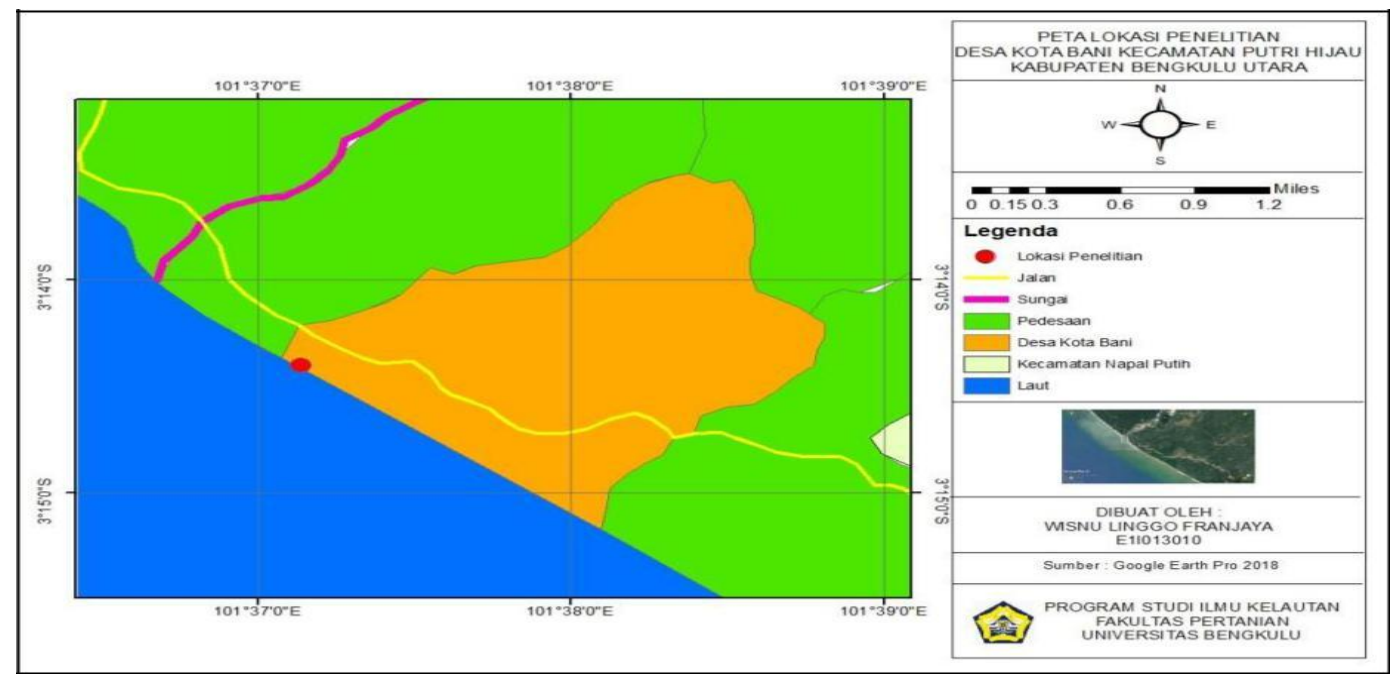

Gambar 1. Peta lokasi penelitian

\section{Metode Penelitian}

Penelitian ini dilakukan dengan metode survei. Ruang lingkup data penelitian meliputi data primer dan data sekunder. Jenis data yang dikumpulkan yaitu : Konstruksi alat tangkap dan bagian-bagian dari alat tangkap, metode pengoperasian alat tangkap, dan produktivitas ikan hasil tangkapan yang menjadi tujuan penangkapan

\section{Studi Lapangan (field research)}

Untuk pelaksanaan pengumpulan data di lapangan peneliti melakukan beberapa kegiatan seperti observasi, wawancara (Interview), dan dokumentasi.

\section{Responden Penelitian}

Untuk pengumpulan data primer diperlukan responden yaitu nelayan pancing rawai dasar yang ada di Desa Kota Bani berdasarkan jumlah unit penangkapan. Maka jumlah responden yang dibutuhkan adalah sebanyak 20\% dari jumlah nelayan pemilik Pancing Rawai Dasar.

\section{Analisis Data}

Data primer yang berkaitan dengan unit penangkapan ikan dengan menggunakan alat tangkap pancing rawai dasar di analisis dengan metode statistik deskriptif. 


\section{Analisis Ukuran Kapal (GT)}

Tangke (2010) dalam Guritno dkk (2016) menyatakan bahwa pengukuran dimensi utama kapal dilakukan untuk mengetahui rasio dimensi utama kapal perikanan, dimana nilai tersebut sangat penting dalam membuat atau mendesain kapal karena akan berpengaruh terhadap kekuatan, kecepatan dan stabilitas kapal perikanan.

Tonnage kapal adalah suatu besaran yang menunjukan kapasitas atau volume ruangan-ruangan yang tertutup dan di anggap kedap air yang berada di dalam kapal. Untuk peritungan grosstonnage (GT) menggunakan rumus di bawah ini (Nomura dan Yamazaki, 1977).

$$
\begin{aligned}
& \mathrm{GT}=\mathrm{L} \times \mathrm{B} \times \mathrm{D} \times \mathrm{Cb} \times 0,353 \\
& \mathrm{Cb}=0,56
\end{aligned}
$$

Keterangan :

$L=$ Panjang Kapal

B $=$ Lebar Kapal

$\mathrm{D}=$ Tinggi Kapal

$\mathrm{Cb}=$ Koefesien blok

\section{Analisis Alat Tangkap Pancing Rawai Dasar}

Alat tangkap pancing rawai dasar ada bagian yang sangat penting dalam pengoperasian untuk menangkap ikan yang berfungsi untuk mengaitkan ikan dan menangkap ikan. Namun di setiap alat tangkap yang dimiliki oleh nelayan Desa Kota Bani Kecamatan Putri Hijau Kabupaten Bengkulu Utara ternyata juga banyak perbedaan dan variasi bentuk lainnya dari alat tangkap Pancing Rawai Dasar tersebut. Maka perlu adanya analisis tentang perbedaan atau variasi lainnya terhadap Pancing Rawai Dasar tersebut yang mendukung keberhasilan unit penangkapan pancing rawai dasar.

\section{Analisis Mesin Perahu/Kapal}

Mesin merupakan bagian penting dari perahu/kapal pada pengoperasian penangkapan ikan yang berfungsi sebagai sarana penggerak perahu/kapal itu sendiri, maka perlu adanya analisis terhadap mesin perahu/kapal guna untuk mendeskripsikan tentang daya/kekuatan, kecepatan dan bahan bakar mesin yang digunakan oleh kapal pancing rawai dasar di Desa Kota Bani Kecamatan Putri Hijau. 


\section{Analisis Anak Buah Kapal (ABK)}

Anak buah kapal adalah semua yang berada dan bekerja di kapal termasuk nahkoda. Jumlah dan keterampilan anak buah kapal berpengaruh terhadap penurunan (setting) dan pengangkatan (hauling).

\section{Analisis Daerah Penangkapan Ikan dan Musim}

Daerah penangkapan dan musim datangnya ikan merupakan bagian yang terpenting dalam melakukan suatu penangkapan ikan, maka perlu adanya analisis daerah penangkapan ikan yang di lakukan turun langsung ke lapangan guna untuk menganalisis jarak lokasi daerah penangkapan ikan secara horizontal, menganalisis kedalaman daerah penangkapan ikan pancing rawai dasar, analisis terhadap daerah penangkapan ikan pancing rawai dasar ini juga di lakukan dengan sistem deskriptif.

\section{Analisis Hasil Tangkapan}

Hasil tangkapan pancing rawai ini dapat dipengaruhi oleh kondisi perairan tiap-tiap daerah dan lokasi pengoperasian alat tangkapan ikan. Analisis hasil tangkapan adalah untuk mengetahui komposisi jenis dan berat ikan hasil tangkapan.

\section{Analisis Produktivitas Alat Tangkap}

Perhitungan produktivitas diperlukan untuk mengetahui efektivitas dan efisiensi usaha. Pengukuran efektivitas dilakukan melalui pendekatan rasio input/output. Pendekatan rasio input/output merupakan model pengukuran produktivitas yang paling sederhana. Data yang didapatakan diukur dan dihitung menggunakan rumus (Gaspersz, 2000).

$$
\text { Produktivitas }=\frac{\text { output } \text { yang dihasilkan }}{\text { input yang dipergunakan }}
$$

Keterangan :

Output yang dihasilkan : hasil tangkapan yang didapat

Input yang dipergunakan : jumlah trip, tenaga kerja, jumlah bensin

Berdasarkan rumus diatas, maka perhitungan produktivitas dilakukan untuk mengetahui :

1) Produktivitas per tahun $=\frac{\text { output }}{\sum \frac{\text { input }}{\text { tahun }}}$

2) Produktivitas per trip $=\frac{\text { output }}{\sum \frac{\text { trip }}{\text { tahun }}}$ 
3) Produktivitas terhadap tenaga kerja (orang) $=\frac{\text { output }}{\sum_{\text {tahun }}^{\text {orahg }}}$

4) Produktivitas terhadap penggunaan BBM (liter)

$$
=\frac{\text { output }}{\sum B B M / \text { liter } / \text { tahun }}
$$

\section{HASIL DAN PEMBAHASAN}

\section{Gambaran Umum Lokasi Penelitian}

Kabupaten Bengkulu Utara adalah salah satu Kabupaten yang terletak di Provinsi Bengkulu, yang ber ibukota kabupaten di Argamakmur. Luas wilayah Kabupaten Bengkulu Utara 4.424,60 $\mathrm{Km}^{2}$. Secara astronomis, Kabupaten Bengkulu Utara terletak antara $2^{\circ} 15^{\prime}$ sampai $4^{\circ} 00^{\prime}$ LS dan antara $101^{\circ} 32^{\prime}$ sampai $102^{\circ} 8^{\prime}$ BT. Kecamatan Putri Hijau terletak dibagian Utara Kabupaten Bengkulu Utara dengan ibu kota di Desa Kota Bani. Kecamatan ini memiliki luas wilayah 188,50 $\mathrm{Km}^{2}$.

Potensi sumberdaya kelautan dan perikanan yang dominan di Desa Kota Bani adalah perikanan tangkap. Namun potensi perikanan ini belum dimanfaatkan dan dikembangkan secara optimal, kerana berbagai faktorfaktor yang tidak mendukung, antara lain fasilitas kegiatan penangkapan yang belum memadai seperti dermaga, tidak adanya pabrik es batu dan fasilitas pendukung lainnya. Perkembangan nelayan sangat diperlukan untuk tercapainya tujuan peningkatan pendapatan serta kesejahteraan masyarakat nelayan.

\section{Unit Penangkapan Ikan Pancing Rawai}

\section{Deskripsi Alat Tangkap Pancing Rawai}

Dari data jumlah kelompok nelayan dan armada alat tangkap diketahui bahwa jumlah alat tangkap ikan dengan Pancing Rawai yang ada di Desa Kota Bani sebanyak 5 unit. Hasil pengamatan langsung di lapangan diperoleh bahwa Pancing Rawai merupakan salah satu alat tangkap yang lebih diminati oleh nelayan Desa Kota Bani, hal ini dikarenakan cara pengoperasiaannya yang relatif cukup mudah serta pembuatan alat tangkap pancing rawai ini juga lebih mudah dan murah dibanding dengan alat tangkap lainnya. Pada prinsipnya pancing rawai ini mempunyai dua komponen utama, yaitu tali pancing yang terdiri dari tali utama dan tali cabang. Tali utama terbuat dari bahan tali tambang dengan ukuran 3 mili dan tali cabang terbuat dari bahan nylon dengan ukuran no 7. Untuk mata pancing dengan ukuran no 7 merk mustad target penangkapan ikan kakap, kerapu, pari dan gaguk. 


\section{Kontruksi Pancing Rawai}

Kontruksi alat tangkap yang digunakan pada penelitian ini terdiri dari tali utama dengan diameter tali sebesar $3 \mathrm{~mm}$ dengan panjang sebesar $1000 \mathrm{~m}$, tali cabang dengan panjang 300-500 meter dengan jarak antar tali $1,5 \mathrm{~m}$, pemberat yang digunakan sebesar 3-5 kg dengan jumlah 5 buah, tali pemberat, pelampung dengan menggunakan bahan gabus berukuran $20 \times 10 \times 5 \mathrm{~cm}$, tali pelampung dan mata pancing pancing yang digunakan dengan ukuran nomor 7 dengan jumlah sebanyak 200 mata pancing. Berbeda dengan hasil penelitian Rahmat (2007) yang menyatakan konstruksi pancing rawai dasar yang digunakan oleh nelayan Kabupaten Barru, Sulawesi Selatan terdiri dari bendera, pemberat $0,5 \mathrm{Kg}$, jangkar $4 \mathrm{Kg}$, dan jarak antar pancing sebesar 5,5 m dengan ukuran mata pancing no 6 atau 8 dengan jumlah sebanyak 480 buah. Sama halnya dengan hasil penelitian Rijal (2004) menyatakan bahwa Pancing Rawai Dasar mempunyai spesifikasi ukuran mata pancing nomor 6 , jarak antara tali pancing $3,5 \mathrm{~m}$, tali pancing senar nomor 40 , panjang tali pancing 1 depa $(1,5 \mathrm{~m})$ dan setiap kali berangkat ke laut kapal membawa sekitar 6.000 mata pancing yang disimpan dalam 6 buah keranjang. Jumlah mata pancing setiap kali beroperasi berkisar antara 2.500 sampai dengan 3.000 mata pancing.

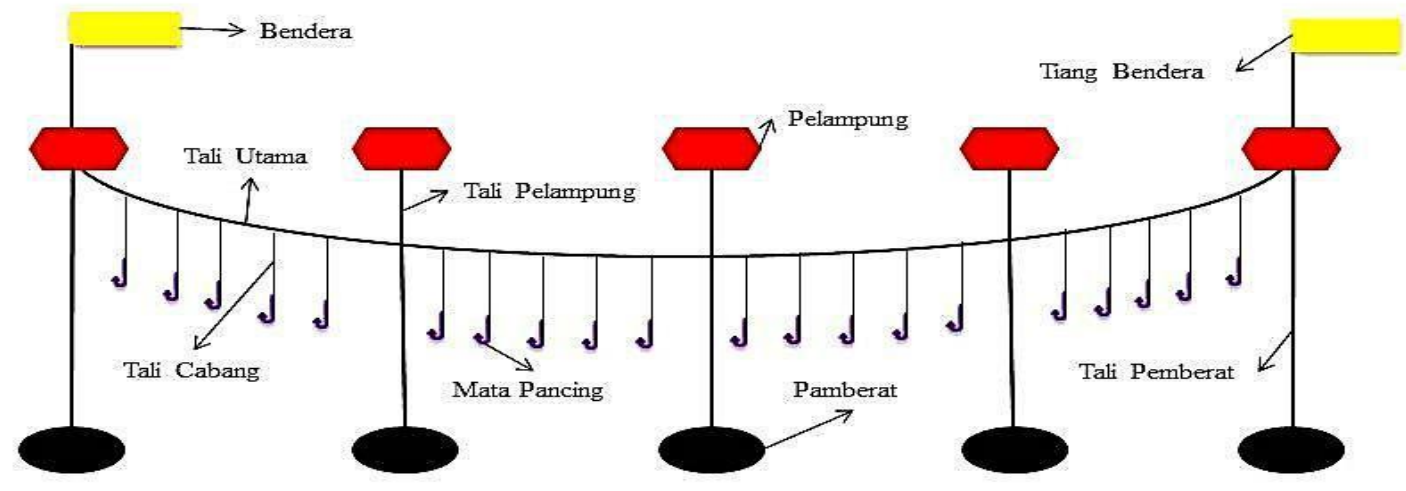

Gambar 2. Konstruksi pancing rawai dasar

\section{Perahu / kapal}

Hasil wawancara kepada nelayan diperoleh data perahu/kapal nelayan di Desa Kota Bani Kecamatan Putri Hijau terbuat dari kayu damar dan jati, dengan kapasitas muatan mencapai 1-2 ton. Daya tahan kapal/perahu di Desa Kota Bani Kecamatan Putri Hijau mecapai 7-8 tahun tergantung dengan perawatan yang dilakukan oleh setiap nelayan. Nelayan di Desa Kota Bani melakukan perawatan perahu/kapal setiap sebulan sekali dengan biaya rata-rata $R p 100.000$,-sampai Rp 200.000,- 
Pengamatan dilapangan terdapat data ukuran perahu/kapal yang dimiliki nelayan Desa Kota Bani Kecamatan Putri Hijau, meliputi panjang kapal, tinggi kapal dan lebar kapal. Nelayan yang memiliki kapal di Desa Kota Bani Kecamatan Putri Hijau adalah Suparman, Jusnan Massa, Rohiman, Yasa Efendi, Ahmad Yani, Hamdani, Jumardi, Bastari dan Asmawi Halmi. Dengan ukuran kapal yang sama yaitu panjang kapal (P) 10 meter, lebar kapal (L) 1,5 meter, tinggi kapal (T) 1 meter dan Grosstonage (GT) 3 GT.

Jenis dan ukuran perahu/kapal sangat berpengaruh terhadap proses penangkapan dan hasil tangkapan ikan. Dimana grosstonage (GT) kapal berukuran besar, maka hasil tangkapan yang diperoleh oleh nelayan juga besar. Dari data yang diperoleh dilapangan terdapat 10 unit perahu/kapal yang dimiliki oleh nelayan Desa Kota Bani Kecamatan Putri Hijau Kabupaten Bengkulu Utara dengan ukuran dan jenis perahu/kapal yang sama. Sehingga ukuran GT perahu/kapal di Desa Kota Bani adalah 3 GT dengan panjang 10 meter, tinggi 1 meter, lebar 1,5 meter dan kapasitas muatan 1-2 ton. Bentuk perahu/kapal di Desa Kota Bani dapat dilihat pada Gambar 3. Berdasarkan hasil penelitian Wangsamulya (2014) mengemukakan bahwa ukuran kapal di Tanjung Pasir Kabupaten Tangerang berukuran 3 - 4 GT dengan panjang 7,5 meter, lebar 2-3 meter, dan tinggi 1-2 meter.

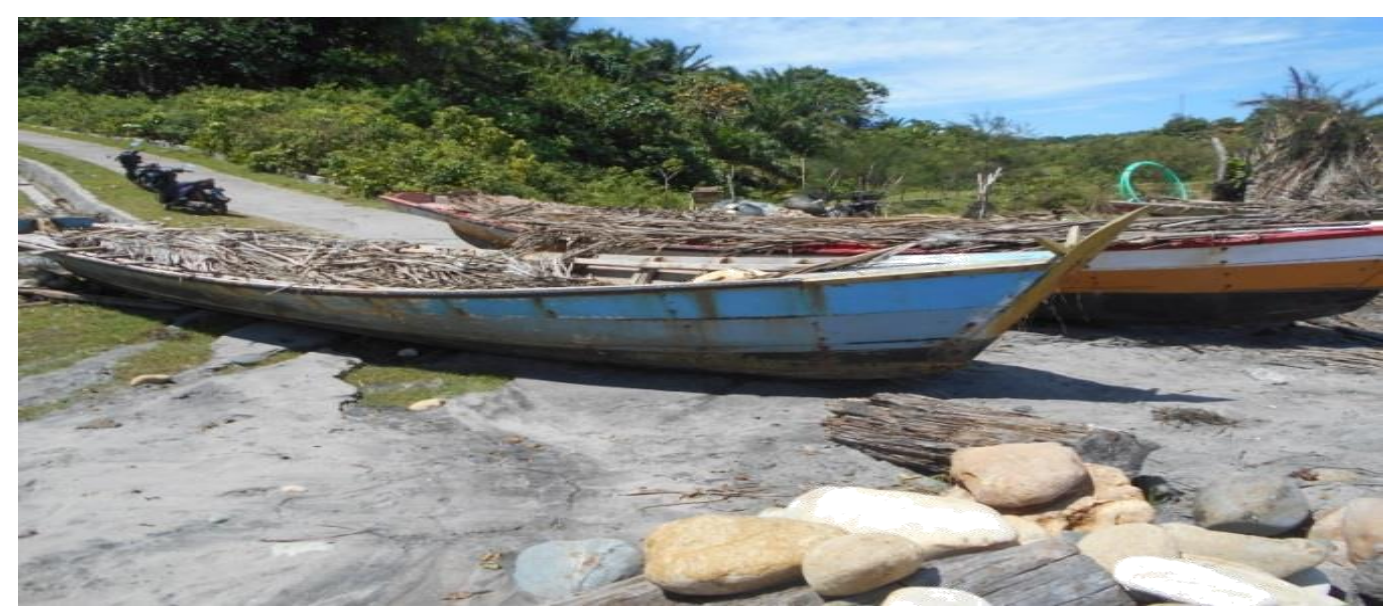

Gambar 3. Perahu/kapal di Desa Kota Bani Kecamatan Putri Hijau

\section{Mesin Perahu / Kapal (PK)}

Hasil pengamatan dilapangan diperoleh data mesin perahu/kapal yang digunakan oleh nelayan Desa Kota Bani Kecamatan Putri Hijau menggunakan mesin merk Yamaha Enduro dengan rata-rata kekuatan perahu/kapal 15 PK berbahan bakar minyak (BBM), kapasitas tank 12 Liter. Bahan bakar minyak yang digunakan adalah pertalite yang dicampur dengan oli 2T merk Castrol. Untuk melakukan satu kali keberangkatan penangkapan nelayan membutuhkan bahan bakar minyak pertalite sebanyak 10 liter yang sudah diberi campuran oli Castrol 2T. berbeda 
dengan hasil penelitian Rahmat (2007) menyatakan bahwa ukuran mesin kapal yang digunakan nelayan pancing rawai dasar di Kabupaten Barru, Sulawesi Selatan lebih dominan menggunakan ukuran 13-16,5 PK.

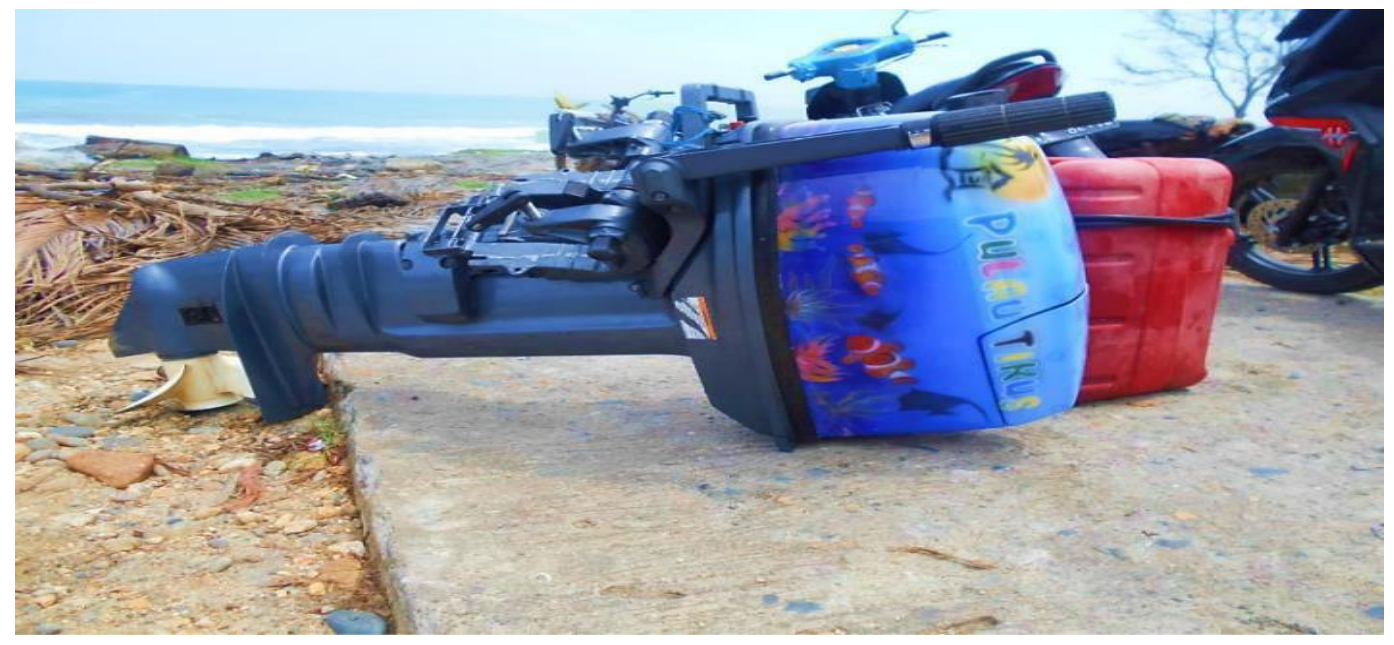

Gambar 4. Mesin kapal

\section{Anak Buah Kapal (ABK)}

Anak buah kapal di Desa Kota Bani Kecamatan Putri Hijau rata-rata terdiri dari orang dan 1 orang nahkoda. Setiap perahu/kapal yang digunakan nelayan Desa Kota Bani terdiri dari 2 orang yaitu nahkoda dan ABK, tetapi fungsi dari 2 orang tersebut sama dan saling membantu untuk mengoperasikan alat tangkap pancing rawai.

Nelayan di Desa Kota Bani Kecamatan Putri Hijau merupakan nelayan tradisional yang menggunakan alat penangkapan ikan yang dilakukan secara sederhana dan manual seperti menggunakan alat tangkap Pancing Rawai Dasar yang dibuat oleh nelayan itu sendiri. Anak buah kapal di Desa Kota Bani Kecamatan Putri Hijau rata-rata terdiri dari orang dan 1 orang nahkoda. Nelayan dan ABK rata-rata berusia 40 - 50 tahun dengan rata-rata pendidikan terakhir adalah SMA dan rata-rata jumlah anak yaitu $5-9$ orang. Setiap perahu/kapal yang digunakan nelayan Desa Kota Bani terdiri dari 2 orang yaitu nahkoda dan ABK, tetapi fungsi dari 2 orang tersebut sama dan saling membantu untuk mengoperasikan alat tangkap Pancing Rawai Dasar. Pendapatan nelayan dan ABK adalah Rp 1.000.000,00 perbulan.

Nelayan di Desa Kota Bani Kecamatan Putri Hujai tidak ada teori dan teknik khusus untuk melakukan penangkapan, karena nelayan dan ABK memiliki pengalaman dalam mengoperasikan alat tangkap dan mengemudi kapal. Pengalaman yang dimiliki Nelayan dan ABK Desa Kota Bani meliputi pengamatan daerah penangkapan, pengoperasian alat tangkap, mengemudi kapal, merawat serta membuat alat tangkap pancing rawai dan pengalaman membuat perahu/kapal. Sistem bagi hasil nelayan 
dan ABK Desa Kota Bani Kecamatan Putri Hijau yaitu 1 : 3 meliputi perawatan operasional penangkapan, nahkoda kapal dan ABK

\section{Metode Pengoperasian Pancing Rawai}

Proses pengoperasian alat tangkap pancing rawai di Desa Kota Bani Kecamatan Putri Hijau dilakukan dengan beberapa kali penurunan alat tangkap. Proses pengoperasian penurunan alat tangkap pancing rawai sesuai dengan musim yaitu musim puncak dilakukan $3-5$ pengulangan penurunan alat tangkap dan sedangkan pada musim paceklik hanya dilakukan 2 kali penurunan alat tangkap. Dari hasil wawancara dengan nelayan, hal tersebut dikarenakan jumlah ikan yang tertangkap dengan alat tangkap pancing rawai sangat berpengaruh terhadap proses pengoperasian alat tangkap.

Pengoperasian alat tangkap pancing rawai tersebut dibagi menjadi beberapa tahap, yaitu persipan pengoperasian, setting, drifting, dan hauling. Pengoperasiannya dilakukan pada pagi sampai sore hari dimulai dari jam 08:00 sampai dengan 15:00 dengan jarak dari sejauh 100-200 meter dari garis pantai. Hal ini senada dengan penelitian Wangsamulya (2014) di Tanjung Pasir Kabupaten Tangerang Satu kali trip penangkapan Pancing Rawai Dasar berlangsung selama 1 hari, dimulai pada pukul 00.00 sampai pukul 08.00 .

\section{Daerah Penangkapan Ikan dan Musim}

Kegiatan penangkapan ikan sangat dipengaruhi oleh musim. Musim penangkapan ikan pancing rawai di Desa Kota Bani terbagi atas 3 musim yaitu musim puncak, musim sedang dan musim paceklik. Jumlah trip penangkapan yang dilakukan oleh nelayan Desa Kota Bani dalam setahun adalah 220 trip. Jumlah trip perbulan adalah 20 trip tergantung dengan musim disetiap bulannya.

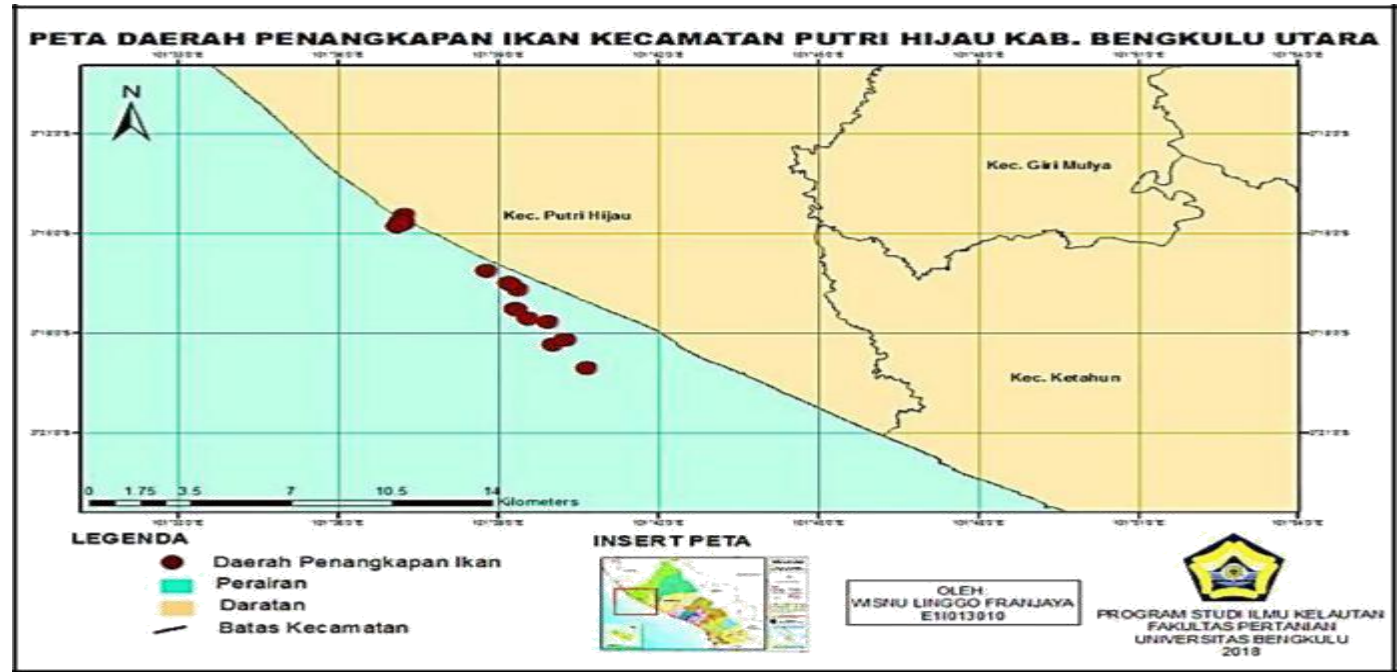

Gambar 5. Peta Daerah Penangkapan Ikan di Kecamatan Putri Hijau 


\section{Analisis Hasil Tangkapan}

Hasil pengamatan dilapangan menunjukkan bahwa hasill tangkapan nelayan pancing rawai terdapat 5 jenis ikan yang tertangkap, yaitu ikan kerapu (Epinephelus sp), ikan kakap merah (Lutjanus malabaricus), ikan pari (Dasyatis sp), ikan hiu putih (Selachimorpha) dan ikan gaguk atau ikan manyung (Arius thalassinus). Hasil tangkapan nelayan Desa Kota Bani dapat dilihat pada Tabel 1. Berdasarkan hasil penelitian Wangsamulya (2014) hasil tangkapan alat tangkap pancing rawai di daerah Tanjung Pasir Kabupaten Tangerang adalah kakap putih (Lates carcarifer), kurisi (Nemipterus celebicus), kuwe (Caranx sexfasciatus), kerapu (Epinephelus sp), barakuda (Sphyraena barracuda), jahan (Nemapteryx macronotacantha), kakap merah (Lutjanus malabaricus), cucut (Carcharinus sp), pari (Dasyatis sp), manyung (Arius maculatus), dan jenaha (Lutjanus synagris). Sedangakan hasil penelitian Rahmat (2007) ikan dominan yang tertangkap adalah jenis ikan kakap dan bambangan ((Lutjanus malabaricus, L. johnii, L. Bohar, dan L. melanostigma), kerapu (C. boenak, E. fuscoguttatus, C. altivelis) dan ikan lencam. Sedangkan jenis-jenis ikan lain yang tertangkap adalah jenis ikan tenggiri, alu-alu, kurisi, bobara, pari, dan lain-lain.

Tabel 1. Komposisi dan Harga Ikan Hasil Tangkapan

\begin{tabular}{clc}
\hline No & \multicolumn{1}{c}{ Jenis Ikan } & Harga \\
\hline 1 & Ikan Kerapu (Epinephelus sp) & $\mathrm{Rp} \mathrm{40.000,00}$ \\
2 & Ikan Kakap Merah (Lutjanus malabaricus) & $\mathrm{Rp} \mathrm{50.000,00}$ \\
3 & Ikan Pari (Dasyatis sp) & $\mathrm{Rp} \mathrm{15.000,00}$ \\
4 & Ikan Hiu Putih (Selachimorpha) & $\mathrm{Rp} \mathrm{75.000,00}$ \\
5 & Ikan Gaguk atau Ikan Manyung (Arius thalassinus) & $\mathrm{Rp} \mathrm{20.000,00}$ \\
\hline
\end{tabular}

\section{Analisis Penanganan dan Pemasaran Hasil Tangkapan}

\section{Penanganan Ikan Diatas Perahu/Kapal}

Hasil pengamatan dan wawancara dilapangan bahwa nelayan Desa Kota Bani melakukan penanganan seadaanya diatas kapal. Berikut proses penanganan ikan diatas perahu/kapal :

1. Melepaskan ikan dari mata pancing

2. Meletakkan ikan pada bagian Dek kapal

3. Setelah semua ikan terlepas dari mata pancing, ikan yang terkumpul diletakkan pada sebuah kantong jaring yang sudah disediakan oleh nelayan 
Pada proses ini tidak adanya penanganan khusus yang dilakukan nelayan terhadap hasil tangkapan mereka. Hal tersebut dikarenakan kurangnya alat yang dimiliki oleh nelayan dan kurangnya kepedulian nelayan terhadap hasil tangkapan tersebut.

\section{Produktivitas Alat Tangkap}

Produktivisatas alat tangkap ditunjukkan pada Tabel 2.

Tabel 2. Produktivitas Alat Tangkap Pancing Rawai Desa Kota Bani Kecamatan Putri Hijau Kabupaten Bengkulu Utara

\begin{tabular}{|c|c|c|c|c|}
\hline \multirow[t]{2}{*}{$\begin{array}{l}\text { Alat } \\
\text { Tangkap } \\
\text { Pancing } \\
\text { Rawai }\end{array}$} & $\begin{array}{l}\text { Produktivitas } \\
\text { Per Tahun } \\
(\mathrm{Kg})\end{array}$ & $\begin{array}{l}\text { Produktivitas } \\
\text { Per Trip (Kg) }\end{array}$ & $\begin{array}{c}\text { Produktivitas } \\
\text { ABK Per Tahun } \\
(\mathrm{Kg})\end{array}$ & $\begin{array}{c}\text { Produk } \\
\text { tivitas } \\
\text { BBM } \\
\text { Per } \\
\text { Tahun } \\
\text { (Liter) }\end{array}$ \\
\hline & 6.000 & 30 & 3.000 & 3 \\
\hline
\end{tabular}

Jumlah perhitungan keseluruhan produktivitas merupakan perhitungan data per tahun. Dari data yang sudah diolah didapat produktivitas trip penangkapan per tahun adalah $3 \mathrm{Kg}$, produktivitas hasil tangkapan per tahun adalah Rp 1.242.000,00, produktivitas ABK per tahun adalah Rp 3.003.000,00, dan produktivitas BBM per tahun adalah Rp 2.788.000,00.

\section{KESIMPULAN}

Kesimpulan yang dapat diambil berdasarkan penelitian ini adalah sebagai berikut :

1. Nilai Produktivitas per tahun $6000 \mathrm{Kg}$, dan nilai Produktivitas Per Trip $30 \mathrm{Kg}$

2. Jenis ikan hasil tangkapan pancing rawai dasar di perairan Desa Kota Bani didominasi Ikan Kerapu (Epinephelus sp), ikan Kakap Merah (Lutjanus malabaricus), Ikan Pari (Dasyatis sp), Ikan Hiu Putih (Selachimorpha), dan Ikan Manyung (Arius thalassinus).

3. Ukuran kapal panjang 10 meter, tinggi 1 meter, lebar 1,5 meter, termasuk ukuran 3 GT dan mesin penggerak yang digunakan adalah mesin tempel 15 PK merk Yamaha 


\section{DAFTAR PUSTAKA}

Bappeda Kabupaten Bengkulu Utara, 2016. Rencana tata Ruang Wilayah Kabupaten Bengkulu Utara 2016-2017. Pemerintah Kabupaten Bengkulu Utara

Gaspersz, V. 2000. Manajemen Produktivitas Total. Jakarta: Penerbit PT. Gramedia Pustaka Utama

Guritno, D., Irnawati. R., Susanto. A. 2016. Karakteristik Dimensi Utama Kapal Purse Seine Di Pelabuhan Perikanan Pantai Lempasing Provinsi Lampung. Jurnal Perikanan dan Kelautan. 6 (1) : 21-30

Nomura. M., Yamazaki. T. 1977. Fishing techniques 1 (compilation of transcript of lectures). Japan International Coorperation Agency. Tokyo. $206 \mathrm{p}$

Pemerintah Provinsi Bengkulu. 2018. Perikanan. Bengkulu. Tersedia pada http://bengkuluprov.go.id/potensi/perikanan/

Rahmat, E. 2007. Penangkapan Ikan Demersal Dengan Pancing rawai dasar di perairan kabupaten Barru, Sulawesi Selatan. Buletin Teknik Litkayasa. 5 (2):65-68

Rosni. 2017. Analisis Tingkat Kesejahteraan Masyarakat Nelayan Di Desa Dahari Selebar Kecamatan Talawi Kabupaten Batubara. Jurnal Geografi. 9 (1) : 53-54

Sadhori. N. 1985. Teknik Penangkapan Ikan. Bandung : Angkasa

Setyorini., Suherman. A., Triarso. I. 2009. Analisis Perbandingan Produktifitas Usaha Penangkapan Ikan Rawai Dasar (Bottom Set Long Line) dan Cantrang (Boat Seine) Di Juwana Kabupaten Pati. Jurnal Saintek Perikanan. 5 (1):7-14

Subri. M. 2005. Ekonomi Kelautan. Jakarta : Raja Grafindo Persada

Syofyan. I., Isnaniah., Siregar. M.R. 2015. Identifikasi dan Analisis Alat Tangkap Rawai Kurau (Mini Long Line) yang Digunakan Nelayan di Kabupaten Bengkalis Jurnal Berkala Perikanan Terubuk. Vol. 43(2):89-95

Tangke, U. 2010. Evaluasi dan Pengembangan Desain Kapal Pole and Line di Pelabuhan Dufa-Dufa Provinsi Maluku Utara. Jurnal IImiah Agribisnis dan Perikanan. 1 (2). 1-10 